Research Paper

\title{
Plasma B-type Natriuretic Peptide Level in Patients with Acute Cerebral Infarction according to Infarction Sub- type and Infarction Volume
}

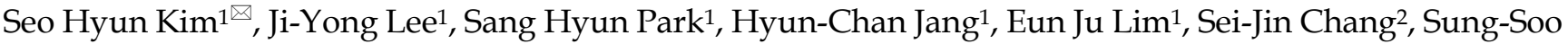 \\ Lee ${ }^{1}$ \\ 1. Department of Neurology, Yonsei University Wonju College of Medicine, Wonju, Kangwon-do, 220-701, Korea \\ 2. Department of Preventive Medicine, Yonsei University Wonju College of Medicine, Wonju, Kangwon-do, 220-701, Korea \\ $\square$ Corresponding author: Seo Hyun Kim, MD, PhD, Department of Neurology, Yonsei University Wonju College of Medicine, 162 Il- \\ san-dong, Wonju, Kangwon-do, 220-701, Korea. Tel: +82-33-741-1252, Fax: +82-33-748-1752, E-mail: s-hkim@yonsei.ac.kr \\ (c) Ivyspring International Publisher. This is an open-access article distributed under the terms of the Creative Commons License (http://creativecommons.org/ \\ licenses/by-nc-nd/3.0/). Reproduction is permitted for personal, noncommercial use, provided that the article is in whole, unmodified, and properly cited.
}

Received: 2012.08.09; Accepted: 2012.12.24; Published: 2012.12.27

\begin{abstract}
Background: Plasma B-type natriuretic peptide (BNP) is used as a diagnostic marker of cardiovascular diseases. BNP is secreted mainly from the myocardium and has been detected by immunoreactivity in brain and cerebral arteries. The aim of our study was to investigate plasma BNP in patients with acute cerebral infarction according to infarction subtype and infarction volume.

Methods: We studied I4I patients with acute cerebral infarction, classified as large artery atherosclerosis (LAA), cardioembolism (CE), or small vessel disease (SA) according to the Trial of Org 10172 in Acute Stroke Treatment classification. Plasma BNP level was measured in patients and $6 \mathrm{I}$ healthy controls. We analyzed various clinical and laboratory variables of patients according to plasma BNP level.

Results: Compared to controls, the patients had higher plasma BNP $(I 1.9 \pm 11.7 \mathrm{pg} / \mathrm{mL}$ versus $124.6 \pm 228.8 \mathrm{pg} / \mathrm{mL}, \mathrm{P}<0.0 \mathrm{l}$ ). The highest quartile BNP group was associated with advanced age, female gender, current non-smoker, atrial fibrillation, heart failure, CE group, increased white blood cell counts, increased high sensitivity C-reactive protein, increased left atrium size, decreased left ventricular ejection fraction, increased initial National Institute of Health Stroke Scale, and increased infarction volume. According to multiple regression analysis, CE group, female gender, and infarction volume were independently associated with plasma BNP. Plasma BNP level showed statistically significant differences among LAA $(n=7 I), C E(n=50)$, and SA $(n=20)$ groups $(p<0.001)$, and the expression decreased in order of CE $(253.8 \pm$ $337.1 \mathrm{pg} / \mathrm{mL})$, LAA $(61.6 \pm 78.8 \mathrm{pg} / \mathrm{mL})$, and SA $(25.3 \pm 24.8 \mathrm{pg} / \mathrm{mL})$. Increased plasma BNP correlated with increased infarction volume $(r=0.42, p<0.00 \mathrm{I})$.

Conclusions: Plasma BNP may be helpful for prediction of etiologic classification of acute cerebral infarction and infarction volume.
\end{abstract}

Key words: cerebral infarction, brain natriuretic peptide, etiology, cardiovascular diseases, embolism, infarction volume

\section{Introduction}

B-type natriuretic peptide (BNP) belongs to a family of natriuretic peptides and is involved in the regulation of various physiologic functions such as natriuresis, diuresis, and vasodilation [1]. Plasma 
BNP is increased in edematous disorders with salt and fluid overload and increased atrial or ventricular wall tension [2]. Increased plasma BNP is a known marker of cardiovascular diseases [1-4]. Plasma BNP level is frequently elevated in acute cerebral infarction and has been associated with cardiac dysfunction, clinical severity, and poor prognosis of cerebral infarction [5-10]. The aim of this study was to investigate plasma BNP in patients with acute cerebral infarction according to variables such as infarction subtype and infarction volume.

\section{Patients and Methods}

Among 236 consecutive patients with acute cerebral infarction who were admitted within three days of onset and whose blood samples were obtained at the time of initial laboratory studies, 141 patients were enrolled and classified as belonging to the large artery atherosclerosis (LAA), cardioembolism (CE), and small vessel disease (SA) groups according to the Trial of Org 10172 in Acute Stroke Treatment (TOAST) classification [11]. Patients with renal dysfunction (serum creatinine $>2.5 \mathrm{mg} / \mathrm{dL}$ ), dialysis dependent renal failure, pulmonary disease such as acute respiratory distress syndrome, chronic obstructive pulmonary disease with cor pulmonale and pulmonary embolism, or thrombolytic therapy were excluded from the study.

Blood was obtained before treatment, and patients were assessed by the National Institute of Health Stroke Scale (NIHSS). Demographic characteristics such as age, gender, smoking, and medical history of hypertension, diabetes mellitus, cardiac disease, and hyperlipidemia were recorded. Blood pressure, heart rate, chest X-ray, electrocardiography, and blood tests including hemoglobin, white blood cell (WBC) count, sugar, cholesterol, blood urea nitrogen, creatinine, BNP, and high sensitivity C-reactive protein (hs-CRP) were measured. Plasma BNP levels were measured by commercially available immunoassay (Biosite Inc., San Diego, CA, USA). Age- and sex-matched normal controls who visited the health care center during the same period were included. The institutional review board approved this study, and informed consent was obtained from the patients or patients' surrogates.

During admission, brain MRI was performed with a 1.5-T system (Gyroscan Intera, Philips Medical Systems) using a multi-slice echo-planar imaging technique to acquire diffusion weighted images (DWIs). The imaging parameters of DWI were as follows: 3400/60/4 (repetition time, msec/effective echo time, msec/excitation), $24 \mathrm{~cm}$ field of view, $5 / 2 \mathrm{~mm}$ slice thickness/gap, and $128 \times 128$ matrix. B values were 0 and $1000 \mathrm{~s} / \mathrm{mm}^{2}$. For the acquisition of the apparent diffusion coefficient, the images were applied in the $x, y$, and $z$ directions. Acute cerebral infarction was defined as an area of high signal intensity on the DWI. Infarction volume was calculated by multiplying the manually contoured hyperintense region by the slice thickness plus the intersection gap with the aid of Scion image software. Areas of acute infarction demonstrated on DWI were measured by an investigator who was not aware of the study purpose.

Complete two-dimensional (2D) and Doppler echocardiographic examinations (GE Vivid7, Philips IE33) were performed by a blinded sonographer. End-diastolic interventricular septum thickness (IVSd), end-diastolic posterior wall thickness (PWDd), end-diastolic left ventricular diameter (LVDd), and left atrium (LA) were measured from the M-mode images. Left ventricular ejection fraction (LVEF) was calculated as end-diastolic minus end-systolic volume divided by end-diastolic volume.

\section{Statistical Analysis}

Plasma BNP levels were not normally distributed and were log-transformed for statistical analysis. T-test, one-factor ANOVA, Chi-square test, Pearson correlation test, and multiple linear regression analysis were performed. Significance was set at $p<0.05$. All statistical analyses were performed using the SPSS 12.0 statistical package (SPSS Inc.).

\section{Results}

\section{Baseline characteristics of normal controls and infarction patients}

Among 141 patients, 71 were classified as LAA, 50 as $\mathrm{CE}$, and 20 as SA. When comparing the baseline characteristics between normal controls and infarction patients, blood pressure, heart rate, WBC count, plasma hs-CRP level, and plasma BNP level were significantly different (Table 1). Mean plasma BNP level was $11.9 \mathrm{pg} / \mathrm{mL}$ in normal controls and 124.6 in patients.

The mean age of the patients was 67.6 years. The patients consisted of 62 women and 79 men, and there were 36 current smokers, 77 with hypertension, 33 with diabetes mellitus, 41 with atrial fibrillation, nine with heart failure, and 15 with hyperlipidemia.

\section{Patient characteristics depending on plasma BNP quartile}

The patients were divided into quartile groups depending on plasma BNP level: first quartile, 23.0 $\mathrm{pg} / \mathrm{mL}$ and below; second quartile, 23 through 52.5; 
third quartile, 52.5 through 140.6; fourth quartile, above 140.6. The mean delay between admission and blood sampling was $33 \pm 40$ minutes and was not different among the groups. Advanced age, female gender, current non-smoker, atrial fibrillation, and heart failure were more prevalent in the highest quartile group compared to the other groups (Table 2). Systolic and diastolic blood pressures were not significantly different among the groups (Table 3 ). Heart rate, WBC count, and plasma hs-CRP level were higher in the highest quartile group compared to the other groups (Table 2, 3). Echocardiographic studies were performed in 103 patients $(73 \%)$, and the mean delay between infarction onset and echocardiographic evaluation was $5.8 \pm 5.1$ days. LVEF was lower and LA size was larger in the highest quartile group compared to the other groups (Table 3). Cardioembolism was more prevalent in the highest quartile group than in the other groups. In addition, there was no SA patient in the highest quartile group (Fig. 1A). Initial NIHSS was higher in the highest quartile group than in the other groups (Table 2, Fig. 1B). A brain DWI was performed in 102 patients, and the mean delay between infarction onset and MRI evaluation was 4.5 \pm 3.5 days. Infarction volume was larger in the highest quartile group than in the other groups (Table 2, Fig. 1C).

\section{Independent association of plasma BNP}

Stepwise multiple linear regression analysis showed that cardioembolism, female gender, and infarction volume were independently associated with plasma BNP level (Table 4). Plasma BNP level showed statistically significant differences among infarction subtypes ( $\mathrm{p}<0.001)$, and the expression of plasma BNP level decreased in order of CE $(253.8 \pm$ $337.1 \mathrm{pg} / \mathrm{mL})$, LAA $(61.6 \pm 78.8 \mathrm{pg} / \mathrm{mL})$, and SA $(25.3$ $\pm 24.8 \mathrm{pg} / \mathrm{mL}$ ) (Fig. 2A). Females had significantly higher plasma BNP level than males (187.5 \pm 314.5 $\mathrm{pg} / \mathrm{mL}$ versus $75.3 \pm 104.8 \mathrm{pg} / \mathrm{mL}, \mathrm{p}<0.001$; Fig. $2 \mathrm{~B}$ ). A significant positive correlation was observed between plasma BNP level and infarction volume $(\mathrm{r}=$ $0.42, \mathrm{p}<0.001$; Fig. 2C).

Table I. Baseline characteristics in normal controls and infarction patients.

\begin{tabular}{llll}
\hline Variable & $\begin{array}{l}\text { Normal controls } \\
(\mathrm{n}=61)\end{array}$ & $\begin{array}{l}\text { Infarction patients } \\
(\mathrm{n}=141)\end{array}$ & p value \\
\hline Age, years & $65.5 \pm 7.3$ & $67.6 \pm 11.6$ & 0.136 \\
Gender, male:female & $40: 21$ & $79: 62$ & 0.206 \\
Current smoker & $11(18.0)$ & $36(26)$ & 0.247 \\
Hypertension & - & $77(55)$ & - \\
Diabetes mellitus & - & $33(23)$ & - \\
Atrial fibrillation & - & $41(29)$ & - \\
Heart failure & - & $9(6)$ & - \\
Hyperlipidemia & - & $15(11)$ & 0.000 \\
Systolic Bp, mmHg & $125.5 \pm 16.5$ & $152.6 \pm 29.1$ & 0.005 \\
Diastolic Bp, mmHg & $80.3 \pm 10.2$ & $85.7 \pm 15.8$ & 0.021 \\
Heart rate, beats/min & $74.8 \pm 12.8$ & $80.4 \pm 20.3$ & 0.000 \\
Serum WBC count, $/ \mathrm{mm}{ }^{3}$ & $5932.6 \pm 1764,3$ & $9065.0 \pm 3556.7$ & 0.949 \\
Serum creatinine, $\mathrm{mg} / \mathrm{dL}$ & $0.9 \pm 0.2$ & $0.9 \pm 0.4$ & 0.000 \\
Plasma hs-CRP level, mg/L & $0.2 \pm 0.4$ & $2.4 \pm 6.7$ & 0.000 \\
Plasma BNP level, $\mathrm{pg} / \mathrm{mL}$ & $11.9 \pm 11.7$ & $124.6 \pm 228.8$ & \\
\hline
\end{tabular}

Values are $\mathrm{n}(\%)$ or mean \pm SD. Bp, blood pressure; WBC, white blood cells; hs-CRP, high sensitivity C-reactive protein; BNP, B-type natriuretic peptide.

Table 2. Patient characteristics according to plasma BNP quartile.

\begin{tabular}{|c|c|c|c|c|c|}
\hline \multirow[t]{2}{*}{ Variable } & \multicolumn{4}{|c|}{ Quartiles of plasma BNP level (pg/mL) } & \multirow[t]{2}{*}{$\mathrm{p}$ value } \\
\hline & $\leq 23.0$ & $23.0-52.5$ & $52.5-140.6$ & $>140.6$ & \\
\hline Age, years & $63.0 \pm 10.6$ & $68.8 \pm 8.9$ & $68.1 \pm 13.8$ & $70.3 \pm 11.7$ & 0.048 \\
\hline Gender, male:female & $25: 10$ & $26: 10$ & $14: 21$ & 14:21 & 0.001 \\
\hline Current smoker & $13(37)$ & $10(28)$ & $8(23)$ & $5(14)$ & 0.026 \\
\hline Hypertension & $19(54)$ & $20(56)$ & $24(69)$ & $14(40)$ & 0.429 \\
\hline Diabetes mellitus & $6(17)$ & $10(28)$ & $7(20)$ & $10(29)$ & 0.412 \\
\hline Atrial fibrillation & $1(3)$ & $3(8)$ & $13(37)$ & $24(69)$ & 0.000 \\
\hline
\end{tabular}




\begin{tabular}{|c|c|c|c|c|c|}
\hline \multirow[t]{2}{*}{ Variable } & \multicolumn{4}{|c|}{ Quartiles of plasma BNP level (pg/mL) } & \multirow[t]{2}{*}{$p$ value } \\
\hline & $\leq 23.0$ & $23.0-52.5$ & $52.5-140.6$ & $>140.6$ & \\
\hline Heart failure & $0(0)$ & $1(3)$ & $3(9)$ & $5(14)$ & 0.009 \\
\hline Hyperlipidemia & $4(11)$ & $5(14)$ & $3(9)$ & $3(9)$ & 0.550 \\
\hline Serum WBC count, $/ \mathrm{mm}^{3}$ & $7901.6 \pm 2666.7$ & $9544.2 \pm 3413.9$ & $7994.6 \pm 2354.3$ & $10237.5 \pm 4569.4$ & 0.010 \\
\hline Serum creatinine, $\mathrm{mg} / \mathrm{dL}$ & $0.8 \pm 0.2$ & $1.0 \pm 0.3$ & $0.8 \pm 0.2$ & $0.9 \pm 0.3$ & 0.070 \\
\hline Plasma hs-CRP level, mg/L & $0.8 \pm 2.7$ & $1.6 \pm 5.3$ & $1.0 \pm 2.1$ & $5.9 \pm 11.0$ & 0.003 \\
\hline Initial NIHSS & $5.3 \pm 5.3$ & $5.1 \pm 5.8$ & $6.4 \pm 5.1$ & $9.0 \pm 7.7$ & 0.031 \\
\hline Infarction volume, $\mathrm{cm}^{3}$ & $5.8 \pm 10.4$ & $11.8 \pm 32.3$ & $26.0 \pm 38.5$ & $47.0 \pm 69.6$ & 0.006 \\
\hline
\end{tabular}

Values are $\mathrm{n}(\%)$ or mean \pm SD. BNP, B-type natriuretic peptide; WBC, white blood cells; hs-CRP, high sensitivity C-reactive protein; NIHSS, National Institute of Health Stroke Scale.

Table 3. Vital sign and echocardiographic findings of patients according to plasma BNP quartile.

\begin{tabular}{|c|c|c|c|c|c|}
\hline \multirow[t]{2}{*}{ Variable } & \multicolumn{4}{|c|}{ Quartiles of plasma BNP level (pg/mL) } & \multirow[t]{2}{*}{$\mathrm{p}$ value } \\
\hline & $\leq 23.0$ & $23.0-52.5$ & $52.5-140.6$ & $>140.6$ & \\
\hline Systolic Bp, mmHg & $149.6 \pm 28.3$ & $158.6 \pm 26.4$ & $153.9 \pm 30.0$ & $147.8 \pm 31.2$ & 0.404 \\
\hline Diastolic Bp, mmHg & $85.1 \pm 15.0$ & $89.6 \pm 14.8$ & $84.7 \pm 17.1$ & $83.5 \pm 15.9$ & 0.387 \\
\hline Heart rate, beats/min & $76.0 \pm 15.8$ & $75.8 \pm 13.3$ & $80.1 \pm 26.3$ & $88.9 \pm 21.5$ & 0.020 \\
\hline LVEF, \% & $73.3 \pm 6.6$ & $70.5 \pm 7.9$ & $64.6 \pm 13.2$ & $54.7 \pm 17.0$ & 0.000 \\
\hline IVSd, cm & $1.08 \pm 0.17$ & $1.12 \pm 0.19$ & $0.99 \pm 0.23$ & $0.99 \pm 0.27$ & 0.119 \\
\hline PWDd, $\mathrm{cm}$ & $1.09 \pm 0.16$ & $1.12 \pm 0.16$ & $1.04 \pm 0.19$ & $0.99 \pm 0.21$ & 0.093 \\
\hline LVDd, $\mathrm{cm}$ & $5.00 \pm 0.46$ & $4.95 \pm 0.42$ & $5.02 \pm 0.66$ & $5.41 \pm 0.76$ & 0.057 \\
\hline LA, cm & $4.34 \pm 0.55$ & $4.53 \pm 0.52$ & $5.13 \pm 0.79$ & $5.01 \pm 0.81$ & 0.000 \\
\hline
\end{tabular}

Values are $\mathrm{n}(\%)$ or mean $\pm \mathrm{SD}$. BNP, B-type natriuretic peptide; Bp, blood pressure; LVEF, left ventricular ejection fraction; IVSd, end-diastolic interventricular septum thickness; PWDd, end-diastolic posterior wall thickness; LVDd, end-diastolic left ventricular diameter; LA, left atrium

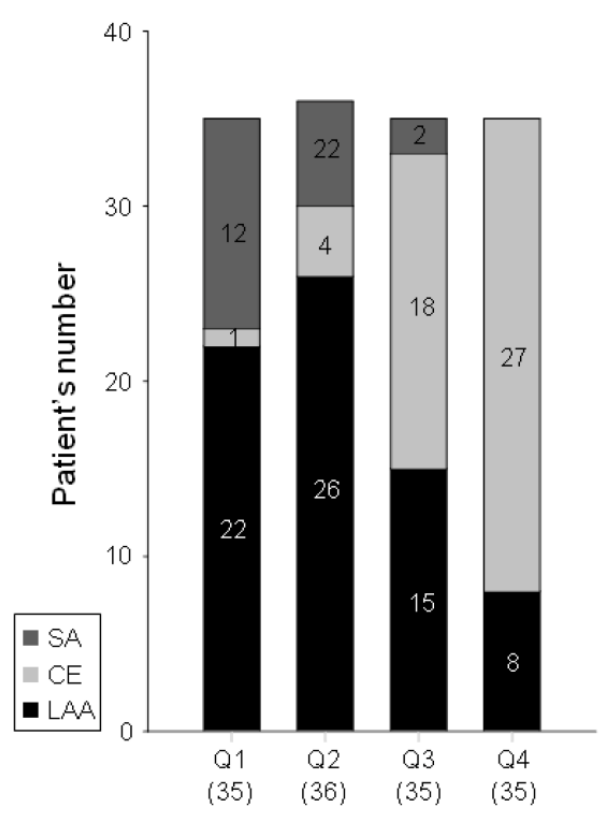

A

BNP quartiles (patient's number)

$(p<0.001)$
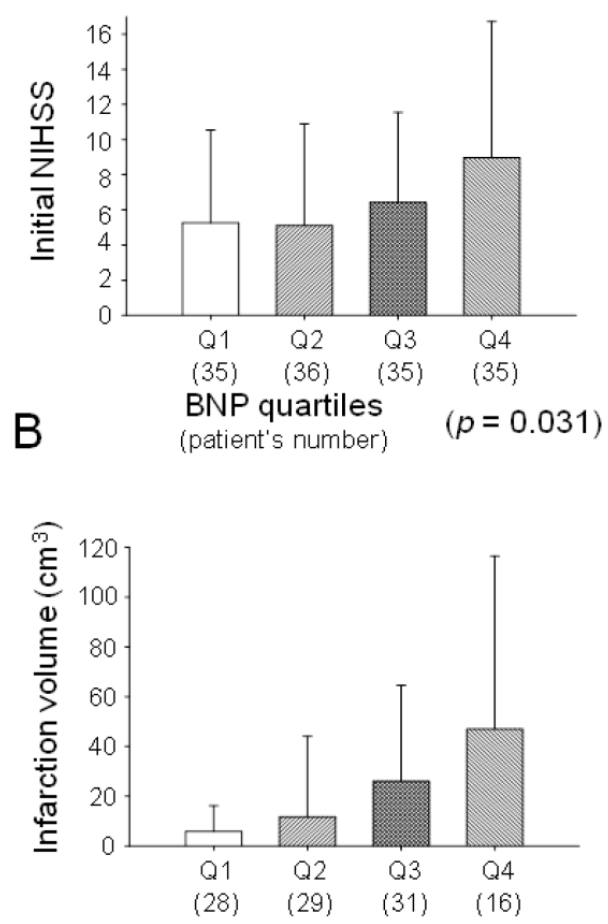

C BNP quartiles

(patient's number)

$(p=0.006)$

Fig. I. Infarction subtypes according to plasma BNP level. Cardioembolism was more prevalent and SA was absent in the fourth quartile group (A). Initial National Institute of Health Stroke Scale (NIHSS) was higher in the fourth quartile group (B). Infarction volume on MRI was higher in the fourth quartile group (C). 
Table 4. Independent associations of plasma BNP.

\begin{tabular}{lllll}
\hline Variable & Beta & Standard Error & $\mathrm{t}$ & $\mathrm{p}$ value \\
\hline CE & 0.402 & 0.211 & 4.849 & 0.000 \\
Female gender & 0.284 & 0.181 & 3.526 & 0.001 \\
Infarction volume & 0.262 & 0.002 & 3.182 & 0.002 \\
\hline
\end{tabular}

$\mathrm{F}=21.048, \mathrm{p}<0.001, \mathrm{R}^{2}=0.402 . \mathrm{CE}$, cardioembolism
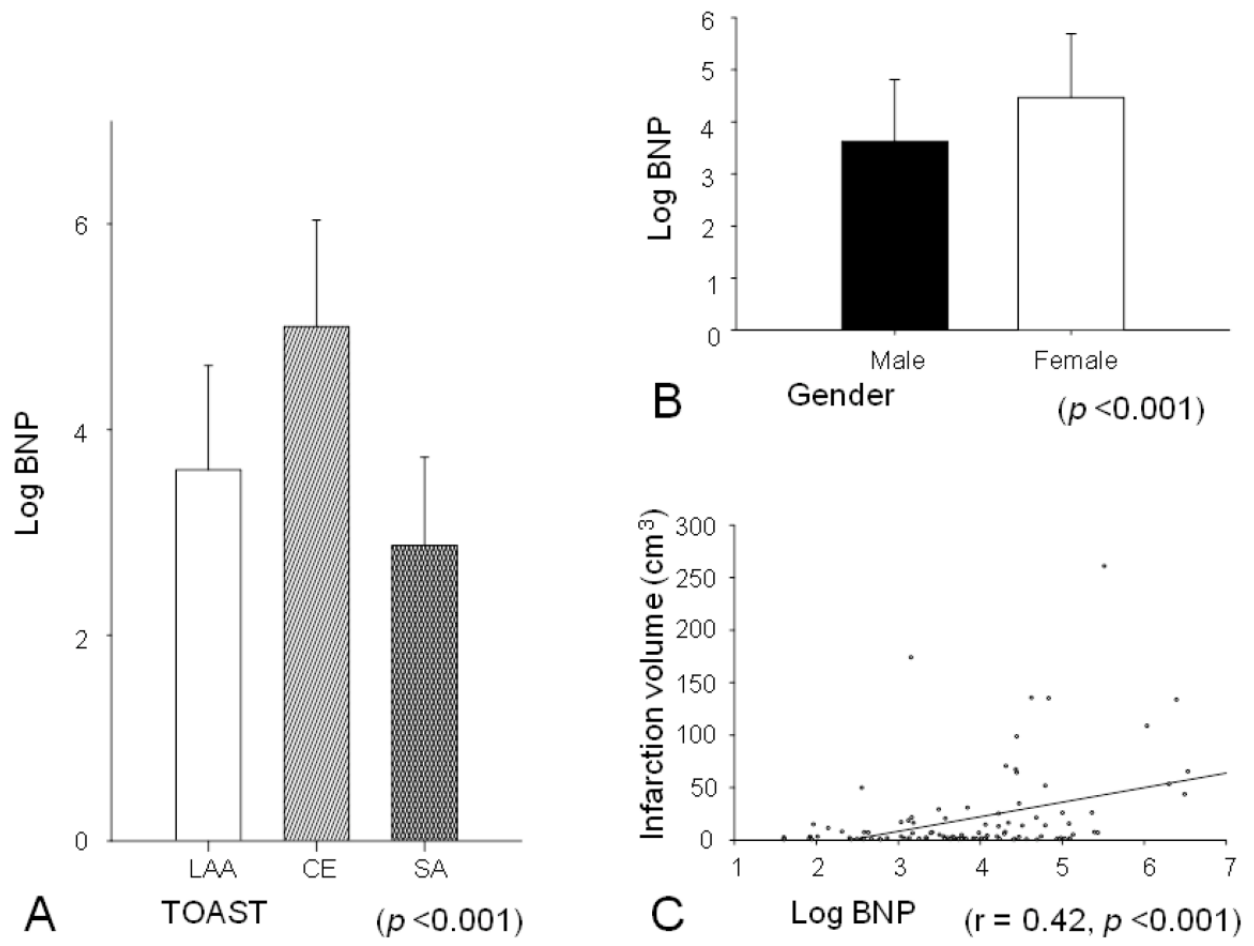

Fig. 2. Plasma BNP levels were significantly different among infarction subtypes, and the expression of BNP decreased in order of CE, LAA, and SA (A). Females had significantly higher plasma BNP levels than males (B). A significant positive correlation was observed between plasma BNP level and infarction volume $(\mathrm{C})$.

\section{Discussion}

In summary, plasma BNP level in patients with acute cerebral infarction was significantly higher than in healthy controls. Advanced age, female gender, current non-smokers, atrial fibrillation, and heart failure were more prevalent; heart rate, WBC count, plasma hs-CRP level, and initial NIHSS were higher; infarction volume was larger; LA size was larger; and LVEF was lower in the fourth quartile group of BNP level compared to the other groups. Plasma BNP level showed statistically significant differences among the infarction subtypes. In addition, cardioembolism, female gender, and infarction volume were independently associated with plasma BNP level.

BNP is a cardiac endocrine hormone and is produced in the myocardium, brain, lungs, kidneys, aorta, and adrenal glands. Regulation of BNP production is believed to occur mostly at the gene ex- pression level [2]. Various hypertrophic and proinflammatory stimuli such as mechanical stretch, ischemia, endothelin-1, angiotensin II, interleukins, and adrenergic agonists can activate BNP gene transcription $[2,12,13]$. BNP is known to have several effects, including natriuresis, diuresis, inhibition of drinking and sympathetic activity in the central nervous system, inhibition of the renin-angiotensin aldosterone system, vascular smooth muscle relaxation, vasodilatation, increase in endothelial permeability, increased lipolysis in adipose tissue, and inhibition of cardiac and vascular remodeling $[2,14]$. Most circulating BNP derives from the ventricular myocardium under pathophysiological conditions such as heart failure, left ventricular dysfunction, atrial fibrillation, acute coronary syndrome, advanced age, female gender, renal dysfunction, pulmonary disease, and high output states [1-4].

Our findings are in agreement with previous 
reports of elevated plasma BNP level in acute cerebral infarction [5-7]. The exact mechanism of elevated BNP level in acute cerebral infarction is unknown, but there are several hypotheses. First, elevated BNP in acute cerebral infarction may be related to cardiac disorders, which may be a cause of the infarction, a co-existing condition, or a result of the infarction [11, 15]. Second, BNP production may be stimulated by changes in catecholamine in acute cerebral infarction, regardless of cardiac dysfunction [1, 16-21]. Third, inflammatory markers or hypoxia-inducible factor that is induced in acute cerebral infarction may stimulate BNP production [21-23]. The fourth quartile group of BNP level in our study had increased inflammatory markers, such as WBC count and hs-CRP level.

Elevated BNP level in acute cerebral infarction has been found to be associated with cardioembolic mechanism, cardiac dysfunction after stroke, clinical severity, thrombolysis failure, and mortality [8-10, 24-29].

We found that plasma BNP level decreased in the order of cardioembolism, large arterial atherosclerosis, and small vessel disease. Most cardiac disorders that are classified as high or medium risks of cardioembolism by TOAST classification are associated with increased plasma BNP level [11]. In addition, many cardiac disorders related to diastolic dysfunction are also associated with elevated BNP [3, 4]. Furthermore, among biomarker candidates of cerebral infarction, elevated plasma BNP level is well correlated with cardioembolic infarction [24, 25]. Acute cerebral infarction that is associated with increased activity of the sympatho-adrenal and renin-angiotensin systems may lead to cardiac dysfunction $[19,20]$. Conventional diagnosis of some cardiac disorders such as paroxysmal atrial fibrillation is time-consuming. In contrast, plasma BNP can be determined within a few minutes and may be useful in the diagnosis of cerebral infarction caused by paroxysmal atrial fibrillation. In addition to cardioembolism, atherosclerosis has also been reported to be associated with elevated BNP $[30,31]$. BNP was highly expressed in advanced atherosclerotic lesions, as visualized by strong in situ hybridization [30], and was reported to correlate with surrogate markers of atherosclerotic burden [31].

We found an independent association of plasma BNP level with female gender. There have been a few studies reporting higher BNP concentrations in females [4]. Sex hormones may contribute to regulation of the production/secretion of natriuretic hormones, with estrogen having stimulatory and androgen having inhibitory effects [21, 32].
In our study, infarction severity was assessed through admission NIHSS and by infarction volume. NIHSS was higher and the infarction volume was larger in the patient group with the highest quartile of plasma BNP level compared to other groups. Infarction volume was independently associated with plasma BNP, and infarction volume and plasma BNP were positively correlated. Plasma BNP has been reported as a marginal predictor of the severity of the admission NIHSS $[8,24]$. However, the relationship between plasma BNP and infarction volume has not yet been confirmed $[6,8]$. Previous reports analyzed the infarction size according to the groups roughly divided into lacunar and territorial. We directly measured the infarction volume on DWIs to analyze the correlation between plasma BNP level and infarction volume. BNP and its receptor are widely distributed in brain regions such as the cerebral cortex, striatum, hypothalamus, preoptic area, cerebellum, and hippocampus [33]. A positive correlation between infarction volume and plasma BNP may suggest that the potential origin of plasma BNP is damaged brain. Expression of mRNA for BNP in rat brain tissue is upregulated after a 24-hour occlusion of the middle cerebral artery [34].

We note that our study has some limitations. The sample size is too small to generalize, and further research with a larger population will be needed. In addition, our study is based on a single test, and repeated tests during cerebral infarction would be more informative. Lastly, we had limited information about neuroendocrine, cardiac, and renal functions.

The exact origin of elevated plasma BNP in acute cerebral infarction and the role of elevated BNP in acute cerebral infarction are currently unknown. Despite this lack of knowledge, BNP may be very useful in identifying and evaluating acute cerebral infarction. Proper treatment requires investigation of the pathomechanism and severity of the infarction at hospital admission. Despite complete evaluations for acute cerebral infarction, substantial numbers of patients have undetermined etiology in TOAST classification [35]. Plasma BNP is not a specific marker for acute cerebral infarction, but it can be quickly determined and is useful to treat patients with acute cerebral infarction through estimation of the pathomechanism and severity of the infarction.

\section{Acknowledgements}

This work was supported by a research grant from Yonsei University Wonju College of Medicine (YUWCM-2010). 


\section{Competing Interests}

The authors have declared that no competing interest exists.

\section{References}

1. Levin ER, Gardner DG, Samson WK. Natriuretic peptides. N Engl J Med. 1998; 339: 321-8.

2. Mair J. Biochemistry of B-type natriuretic peptide--where are we now? Clin Chem Lab Med. 2008; 46: 1507-14.

3. Daniels LB, Maisel AS. Natriuretic peptides. J Am Coll Cardiol. 2007; 50: 2357-68.

4. Balion CM, Santaguida P, McKelvie R, Hill SA, McQueen MJ, Worster A, et al. Physiological, pathological, pharmacological, biochemical and hematological factors affecting BNP and NT-proBNP. Clin Biochem. 2008; 41: 231-9.

5. Lynch JR, Blessing R, White WD, Grocott HP, Newman MF, Laskowitz DT. Novel diagnostic test for acute stroke. Stroke. 2004; 35: 57-63.

6. Nakagawa K, Yamaguchi T, Seida M, Yamada S, Imae S, Tanaka Y, et al. Plasma concentrations of brain natriuretic peptide in patients with acute ischemic stroke. Cerebrovasc Dis. 2005; 19: 157-64.

7. Cakir Z, Saritas A, Emet M, Aslan S, Akoz A, Gundogdu F. A prospective study of brain natriuretic peptide levels in three subgroups: Stroke with hypertension, stroke without hypertension, and hypertension alone. Ann Indian Acad Neurol. 2010; 13: 47-51.

8. Di Angelantonio E, De Castro S, Toni D, Sacchetti ML, Biraschi F, Prencipe $\mathrm{M}$, et al. Determinants of plasma levels of brain natriuretic peptide after acute ischemic stroke or TIA. J Neurol Sci. 2007; 260: 139-42.

9. Makikallio AM, Makikallio TH, Korpelainen JT, Vuolteenaho O, Tapanainen JM, Ylitalo K, et al. Natriuretic peptides and mortality after stroke. Stroke. 2005; 36: 1016-20.

10. Shibazaki K, Kimura K, Okada Y, Iguchi Y, Uemura J, Terasawa Y, et al. Plasma brain natriuretic peptide as an independent predictor of in-hospital mortality after acute ischemic stroke. Intern Med. 2009; 48: 1601-6.

11. Adams HP, Jr., Bendixen BH, Kappelle LJ, Biller J, Love BB, Gordon DL, et al. Classification of subtype of acute ischemic stroke. Definitions for use in a multicenter clinical trial. TOAST. Trial of Org 10172 in Acute Stroke Treatment. Stroke. 1993; 24: 35-41.

12. LaPointe MC. Molecular regulation of the brain natriuretic peptide gene. Peptides. 2005; 26: 944-56.

13. Martinez-Rumayor A, Richards AM, Burnett JC, Januzzi JL, Jr. Biology of the natriuretic peptides. Am J Cardiol. 2008; 101: 3-8.

14. Porzionato A, Macchi V, Rucinski M, Malendowicz LK, De Caro R. Natriuretic peptides in the regulation of the hypothalamic-pituitary-adrenal axis. Int Rev Cell Mol Biol. 2010; 280: 1-39.

15. Myers MG, Norris JW, Hachinski VC, Weingert ME, Sole MJ. Cardiac sequelae of acute stroke. Stroke. 1982; 13: 838-42.

16. Schwarz S, Schwab S, Klinga K, Maser-Gluth C, Bettendorf M. Neuroendocrine changes in patients with acute space occupying ischaemic stroke. J Neurol Neurosurg Psychiatry. 2003; 74: 725-7.

17. Fassbender K, Schmidt R, Mossner R, Daffertshofer M, Hennerici M. Pattern of activation of the hypothalamic-pituitary-adrenal axis in acute stroke. Relation to acute confusional state, extent of brain damage, and clinical outcome. Stroke. 1994; 25: 1105-8.

18. Fujishima S, Abe I, Okada Y, Saku Y, Sadoshima S, Fujishima M. Serial changes in blood pressure and neurohormone levels after the onset of lacunar stroke. Angiology. 1996; 47: 579-87.

19. Myers MG, Norris JW, Hachniski VC, Sole MJ. Plasma norepinephrine in stroke. Stroke. 1981; 12: 200-4.

20. Koenig M, Puttgen H, Prabhakaran V, Reich D, Stevens R. B-type natriuretic peptide as a marker for heart failure in patients with acute stroke. Intensive Care Med. 2007; 33: 1587-93.

21. Clerico A, Giannoni A, Vittorini S, Passino C. Thirty years of the heart as an endocrine organ: physiological role and clinical utility of cardiac natriuretic hormones. Am J Physiol Heart Circ Physiol. 2011; 301:H12-20.

22. Shi H. Hypoxia inducible factor 1 as a therapeutic target in ischemic stroke. Curr Med Chem. 2009; 16: 4593-600.

23. Weidemann A, Klanke B, Wagner M, Volk T, Willam C, Wiesener MS, et al. Hypoxia, via stabilization of the hypoxia-inducible factor HIF-1alpha, is a direct and sufficient stimulus for brain-type natriuretic peptide induction. Biochem J. 2008; 409: 233-42.
24. Montaner J, Perea-Gainza M, Delgado P, Ribo M, Chacon P, Rosell A, et al. etiologic diagnosis of ischemic stroke subtypes with pasma biomarkers. Stroke. 2008; 39: 2280-7.

25. Shibazaki K, Kimura K, Iguchi Y, Okada Y, Inoue T. Plasma brain natriuretic peptide can be a biological marker to distinguish cardioembolic stroke from other stroke types in acute ischemic stroke. Inten Med. 2009; 48: 259-64.

26. Okada Y, Shibazaki K, Kimura K, Matsumoto N, Iguchi Y, Aoki J, et al. Brain natriuretic peptide is a marker associated with thrombus in stroke patients with atrial fibrillation. J Neurol Sci. 2011; 301: 86-9.

27. Shibazaki K, Kimura K, Okada Y, Iguchi Y, Terasawa Y, Aoki J. Heart failure may be associated with the onset of ischemic stroke with atrial fibrillation: A brain natriuretic peptide study. J Neurol Sci. 2009; 281: 55-7.

28. Kimura K, Shibazaki K, Iguchi Y, Aoki J, Sakai K, Sakamoto Y, et al. The combination of elevated BNP and AF as a predictor of no early recanalization after IV-t-PA in acute ischemic stroke. J Neurol Sci. 2010; 290: 37-40.

29. Jensen JK, Atar D, Kristensen SR, Mickley H, Januzzi Jr JL. Usefulness of natriuretic peptide testing for long-term risk assessment following acute ischemic stroke. The Am J Cardiol. 2009; 104: 287-91.

30. Casco VH, Veinot JP, Kuroski de Bold ML, Masters RG, Stevenson MM, de Bold AJ. Natriuretic peptide system gene expression in human coronary arteries. J Histochem Cytochem. 2002; 50: 799-809.

31. Ashley KE, Galla JM, Nicholls SJ. Brain natriuretic peptides as biomarkers for atherosclerosis. Prev Cardiol. 2008; 11: 172-6.

32. Clerico A, Fontana M, Vittorini S, Emdin M. The search for a pathophysiological link between gender, cardiac endocrine function, body mass regulation and cardiac mortality: proposal for a working hypothesis. Clin Chim Acta. 2009; 405: 1-7.

33. Cao LH, Yang XL. Natriuretic peptides and their receptors in the central nervous system. Prog Neurobiol. 2008; 84: 234-48.

34. Brosnan MJ, Clark JS, Jeffs B, Negrin CD, Van Vooren P, Arribas SM, et al. Genes encoding atrial and brain natriuretic peptides as candidates for sensitivity to brain ischemia in stroke-prone hypertensive rats. Hypertension. 1999; 33: 290-7.

35. Lee BI, Nam HS, Heo JH, Kim DI. Yonsei Stroke Registry. Analysis of 1,000 patients with acute cerebral infarctions. Cerebrovasc Dis. 2001; 12: 145-51. 